\title{
Glucocorticoids Accelerate Fetal Maturation of the Epidermal Permeability Barrier in the Rat
}

\author{
Michelle Aszterbaum, * Kenneth R. Feingold, ** Gopinathan K. Menon, * and Mary L. Williams, *s \\ Departments of ${ }^{*}$ Dermatology, ${ }^{\ddagger}$ Medicine, and ${ }^{\$}$ Pediatrics, University of California, San Francisco, San Francisco, California 94143 ; \\ and the ${ }^{*}$ Dermatology and ${ }^{\ddagger}$ Medical Services Department of Veterans Affairs Medical Center, San Francisco, California 94121
}

\begin{abstract}
The cutaneous permeability barrier to systemic water loss is mediated by hydrophobic lipids forming membrane bilayers within the intercellular domains of the stratum corneum (SC). The barrier emerges during day 20 of gestation in the fetal rat and is correlated with increasing SC thickness and increasing SC lipid content, the appearance of well-formed lamellar bodies in the epidermis, and the presence of lamellar unit structures throughout the SC. Because glucocorticoids accelerate lung lamellar body and surfactant maturation in man and experimental animals, these studies were undertaken to determine whether maternal glucocorticoid treatment accelerates maturation of the epidermal lamellar body secretory system. Maternal rats were injected with betamethasone or saline (control) on days 16-18, and pups were delivered prematurely on day 19. Whereas control pups exhibited immature barriers to transepidermal water loss $\left(8.16 \pm 0.52 \mathrm{mg} / \mathrm{cm}^{2}\right.$ per $\left.\mathrm{h}\right)$, glucocorticoidtreated pups exhibited competent barriers $\left(0.74 \pm 0.14 \mathrm{mg} / \mathrm{cm}^{2}\right.$ per h; $P<0.001$ ). Glucocorticoid treatment also: (a) accelerated maturation of lamellar body and SC membrane ultrastructure; (b) increased SC total lipid content twofold; and (c) increased cholesterol and polar ceramide content three- to sixfold. Thus, glucocorticoids accelerate the functional, morphological, and lipid biochemical maturation of the permeability barrier in the fetal rat. (J. Clin. Invest. 1993. 91:27032708.) Key words: epidermal lamellar body • stratum corneum lipids • transepidermal water loss • permeability barrier
\end{abstract}

\section{Introduction}

A competent cutaneous barrier to systemic water loss is an essential requirement for extrauterine life. In humans (1-4), as in other mammals $(5,6)$, barrier competence is established during late gestation. Preterm infants less than 34 wk gestational age (GA) ${ }^{1}$ demonstrate increased transepidermal water loss (TEWL) and percutaneous absorption of xenobiotics in proportion to their degree of prematurity (1-4). While the

A preliminary report of this work appeared in 1992. (Clin. Res. 40:309a). Address correspondence to Mary L. Williams, M.D., Dermatology Service (190), Department of Veterans Affairs Medical Center, 4150 Clement Street, San Francisco, CA 94121.

Received for publication 2 October 1992 and in revised form 6 January 1993.

1. Abbreviations used in this paper: GA. gestational age; SC, stratum corneum; TEWL, transepidermal water loss; $\beta$-Rx, betamethasone treated.

The Journal of Clinical Investigation, Inc.

Volume 91, June 1993, 2703-2708 consequences of barrier immaturity can be devastating, and include fluid and electrolyte imbalance, increased energy expenditure to compensate for evaporative heat loss, and transcutaneously acquired infection (7-9), barrier ontogenesis has received little attention.

In mature skin, it is well recognized that the permeability barrier resides in the outermost anucleate epidermal cell layers, the stratum corneum (SC) (10). The barrier is provided by a complement of relatively hydrophobic lipid species, predominantly cholesterol, ceramides, and free fatty acids, arranged in multiple lamellar bilayers between corneocytes (11). Both polar lipid precursors of these lipids and hydrolytic enzymes required for their processing are delivered to the SC extracellular domains through secretion of a tissue-specific organelle, the epidermal lamellar body $(12,13)$. After secretion, their internal membranes unfurl (14) and reorganize to form a repeating pattern of electron-lucent (hydrophobic) and electron-dense (hydrophilic) lamellae (15), termed the basic lamellar bilayer unit structure (16).

Recently we demonstrated that the development of a competent permeability barrier in the fetal rat correlates with increasing SC lipid content, particularly cholesterol and nonpolar ceramide content, and with maturation of epidermal lamellar body substructure and SC lamellar membrane ultrastructure (6). The timetable for barrier maturation in the fetal rat is strikingly similar to that previously observed for lung surfactant maturation $(17,18)$. This parallel is intriguing because, like epidermis, the lung alveolar Type II cell utilizes an analogous secretory organelle (the lung lamellar body) for delivery of surfactant to the extracellular domains of the alveolus. Because certain hormones, particularly glucocorticoids, have been shown to accelerate lung lamellar body and surfactant maturation in humans and experimental animals ( reviewed in $19,20)$, we asked whether glucocorticoids similarly accelerate maturation of the barrier and the epidermal lamellar body secretory system in the fetal rat.

\section{Methods}

Materials. Ruthenium tetroxide and nile red were obtained from Polysciences, Inc. (Warrington, PA) and $\mathrm{OCT}^{\mathrm{R}}$ compound from Miles Scientific Div. (Naperville, IL) Authentic lipid standards were purchased from Sigma Chemical Co. (St. Louis, MO) and Avanti Polar Lipids, Inc. (Pelham, AL). The "acylceramide" standard, BRS-001 ( $N$-[ $\omega-$ linoleoyloxy)-palmitoyl]- $N$-[3-(cetyl-ether)-isopropanyl]-ethanolamine), was a generous gift of Dr. Genji Imokawi, Kao Corporation. High performance silica gel TLC plates were purchased from Merck (Darmstadt, Germany).

Transepidermal water loss (TEWL) and tissue preparation. Timed-pregnant $($ plug date $=$ day 0 ) primiparous Sprague-Dawley rats (6-10 wk old) (Simonsen Laboratories, Gilroy, CA) were injected intramuscularly with betamethasone $(1 \mathrm{mg} / \mathrm{kg}$; Schering Corp., Kenilworth, $\mathrm{NJ}$ ) or saline on days 16,17 , and 18 , and premature rat pups 
were obtained by Cesarean section on day 19. TEWL was measured within $1 \mathrm{~h}$ of birth as described (6), using an electrolytic moisture analyzer (Meeco; Polysciences) (21). Data are expressed as $\mathrm{mg}_{2} \mathrm{O}$ / $\mathrm{cm}^{2}$ per $\mathrm{h}(22)$, mean \pm SE. For statistical purposes, off-scale readings (i.e., TEWL $>10 \mathrm{mg} / \mathrm{cm}^{2}$ per h) were recorded as $10 \mathrm{mg} / \mathrm{cm}^{2}$ per $\mathrm{h}$. Significance was determined using a two-tailed Student's $t$ test. Pups were then weighed, killed, and epidermal-dermal and stratum corneum separations were obtained as described (6).

Thin-layer chromatography. Lipids were extracted from the SC sheets, weighed (23), and fractionated by high performance TLC, followed by charring and scanning densitometry as described $(6,24)$. For quantitation of ceramides, $8 \mu \mathrm{g}$ of each fetal sample was applied in a 0.5-cm lane. Plates were developed twice in chloroform $/ \mathrm{methanol} /$ acetic acid (95:4:1, vol) to the top, and ceramide fractions were quantitated in reference to the closest migrating ceramide standard. Ceramide fractions are designated 1 to 7 in order of decreasing $R_{\mathrm{f}}$.

Light and electron microscopy. Fetal rat skin for light microscopy was embedded in $\mathrm{OCT}^{\mathrm{R}}$ compound, sectioned, and nile red ( $100 \mu \mathrm{g} /$ $\mathrm{ml}, 75 \%$ glycerol ) applied (25). Sections were examined with a Nikon Microphot-FX microscope equipped with epifluorescence (excitation of $470-490 \mathrm{~nm}$, emission $520 \mathrm{~nm}$ ). Full-thickness fetal rat skin was processed for electron microscopy, double-stained with uranyl acetate and lead citrate or lead citrate alone, and examined in a Zeiss $10 \mathrm{~A}$ electron microscope operating at $60 \mathrm{kV}(6)$.

\section{Results}

Transepidermal water loss (TEWL). To determine whether glucocorticoids accelerate fetal barrier maturation, maternal rats were injected with either betamethasone $(\beta-R x)$ or saline (control) on days 16, 17, and 18 of gestation, and TEWL was determined in their pups on day 19 (Fig. 1). As expected, 19-d GA pups of control mothers exhibit poor barriers to water loss (TEWL: $8.16 \pm 0.52$ [ $>10$ to 2.12 ] $\mathrm{mg} / \mathrm{cm}^{2}$ per $\mathrm{h}$; mean $\pm \mathrm{SE}$ [range]); in most, no measurable barrier was present. In contrast, all 19-d GA pups of $\beta$-Rx mothers exhibit measurable barriers, and in most, the barrier was highly competent (TEWL: $0.74 \pm 0.14$ [3.89 to 0.21$] ;[P<0.001]$ ). Their barrier competence approaches that observed during normal rat development on day 21 (TEWL: $0.14 \pm 0.02 \mathrm{mg} / \mathrm{cm}^{2}$ per $\mathrm{h}$ ) (6). Thus, maternal glucocorticoid treatment accelerates epidermal barrier maturation by $\sim 2 \mathrm{~d}$. Moreover, this acceleration occurs despite an $\sim 25 \%$ decrease in fetal size of $\beta$-Rx pups ( $2.44 \pm 0.08$ vs. $1.79 \pm 0.03 \mathrm{~g}$; mean body weight $\pm S E$, control vs. $\beta$ - $\operatorname{Rx} P<0.001)$. Somatic growth retardation is a well-recognized effect of glucocorticoid treatment in the fetal rat (26).

Fluorescence microscopy. Skin samples from two control and two $\beta-\operatorname{Rx} 19-\mathrm{d}$ GA pups were examined by nile red histo-

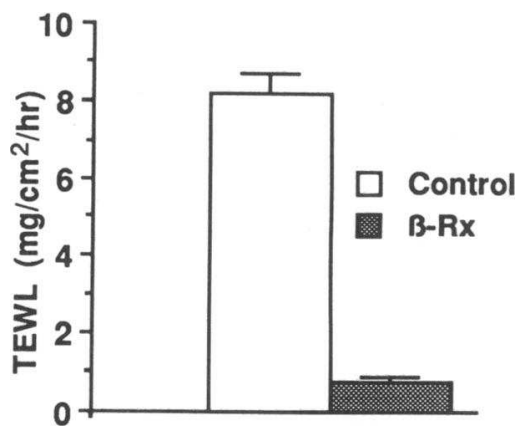

Figure 1. Transepidermal water loss in 19-d GA rat pups from control vs. $\beta$-Rx mothers. Maternal rats were injected with saline (control) or betamethasone on days $16-18$ of gestation, and TEWL was measured in their pups on day 19 . The difference in mean TEWL between control ( $n$

$=27$, open bar $)$ and $\beta-\operatorname{Rx}(n=31$, hatched bar $)$ is highly significant $(P<0.001)$. (Vertical bars indicate the SEM.) chemistry. The morphology of control epidermis is shown in Fig. $2 \mathrm{~A}$. Note that the SC is poorly defined at this age. Red-orange fluorescent material indicative of polar lipid (25) is evident in the outermost epidermal layers, forming a homogeneous or somewhat beaded (open arrows) pattern (Fig. $2 \mathrm{~A}$ ). Keratohyalin granules (closed arrow) are small and infrequent. In contrast, the epidermis of $19-\mathrm{d}$ rat pups from $\beta$-Rx mothers exhibits a well-defined, multilayered SC (Fig. $2 B$ ). A mature, membrane pattern (Fig. $2 B$, open arrows) of orange-yellow nile-red fluorescence (27) is present in the outermost layers, indicative of the deposition of neutral lipid in the membrane domains of the SC. Keratohyalin granules (Fig. $2 \mathrm{~B}$, closed arrows) are large and numerous in upper nucleated cell layers of $\beta$-Rx epidermis. While epidermis of control pups is comparable in its light microscopic features with that previously reported for 19-d GA rat skin during normal ontogenesis, the epidermis of $\beta$ - Rx rat pups exhibits morphologic features comparable with normal rat skin at $21 \mathrm{~d} \mathrm{GA}(6)$.
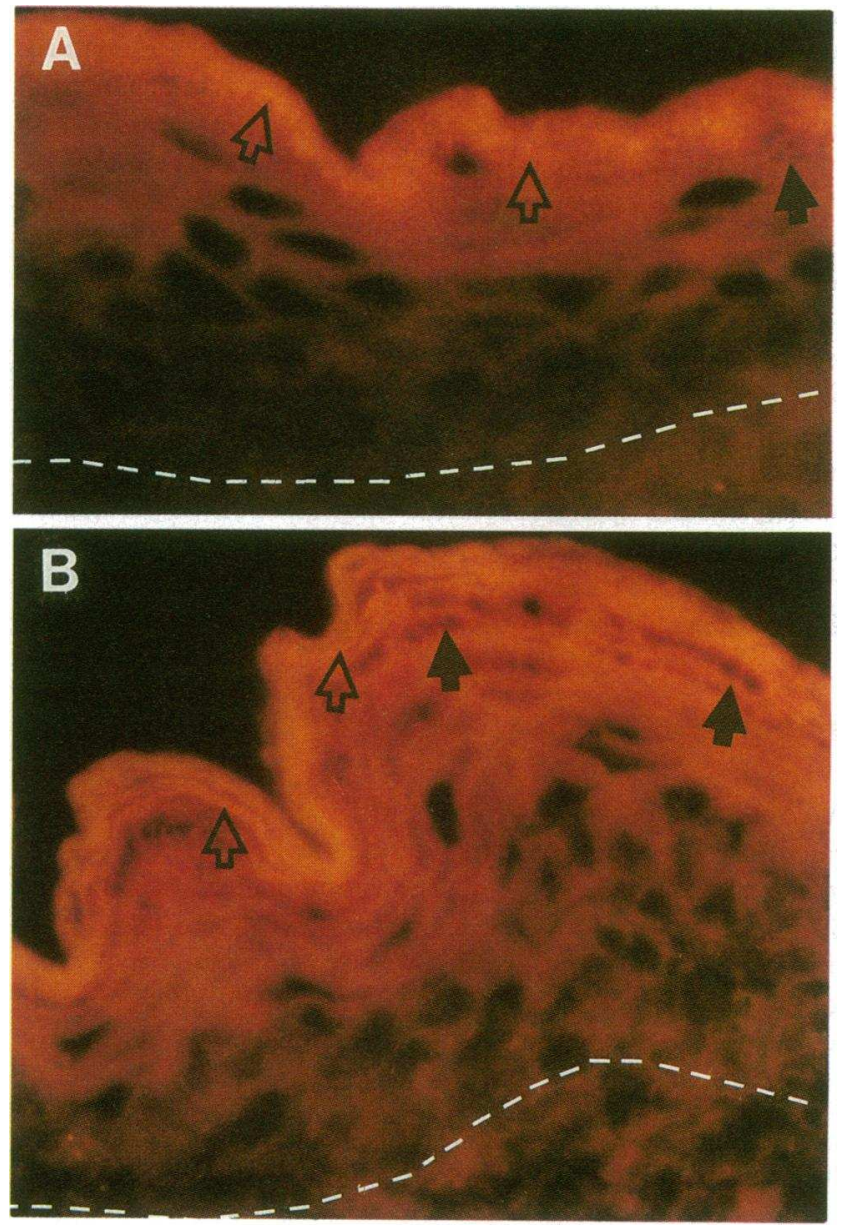

Figure 2. Representative nile red histochemistry of 19-d fetal rat epidermis. $(A)$ Control. Note deposition of lipid in a homogenous or beaded pattern (open arrows) in outer epidermal layers. A well-defined SC is not present. Keratohyalin granules (closed arrow) are small and few in number. $(B) \beta$-Rx. Note the presence of a well-defined, multilayered SC. Lipid is deposited in a membranous pattern in the SC (open arrow) and numerous, large keratohyalin granules (closed arrows) are seen. Dashed lines represent the approximate region of the dermal-epidermal junction. 
Electron microscopy. Epidermis of three control and three $\beta$-Rx 19-d GA pups was examined by transmission electron microscopy. Although lamellar bodies are present in control SC (Fig. $3 C$ ), most lack the mature pattern of disclike lamellations (closed arrow), thus appearing "empty" (open arrows). Abundant lamellar-body-derived material is evident between the cornified cells (Fig. $3 \mathrm{~A}$ ). However, transformation to basic lamellar unit structures is not observed (Fig. $3 \mathrm{~B}$, closed arrows). Focal empty-appearing regions (Fig. 3 , open arrows) are evident throughout the membrane regions of the SC (Fig. $3 A$ ). These ultrastructural features are comparable with those previously described for 19-d GA rat epidermis during normal ontogenesis (6). In contrast, $\mathrm{SC}$ from $\beta-\mathrm{Rx}$ pups exhibits ultrastructural features not normally expected until day 21 (Fig. 4). Epidermal lamellar bodies more frequently exhibit a complete internal membranous substructure (Fig. 4 $C$ ). Moreover, a multilayered SC is evident (Fig. $4 A$ ), in which secreted lamellar body contents at the $\mathrm{SC}$-stratum granulosum interface (Fig. $4 \mathrm{~B}$ ) are reorganized to form the mature pattern of basic lamellar unit structures (Fig. $4 A$, open arrows). Furthermore, these lamellar unit structures extend throughout all layers of the SC (Fig. $4 A$ ).

Lipid biochemistry. The lipid content of SC sheets isolated from 19-d rat pups of $\beta$-Rx mothers is nearly twofold greater than from control pups $(33.98 \pm 2.58(n=7)$ vs. $63.54 \pm 3.84$ ( $n$ $=15) \mathrm{mg}$ lipid $/ \mathrm{cm}^{2}$, mean $\pm \mathrm{SE}$ control vs. $\beta-R x$, respectively;
$P<0.001$ ). The overall sphingolipid content of SC ( $\mu \mathrm{g}$ lipid/ $\left.\mathrm{cm}^{2}\right)$ is increased 2.5 -fold by $\beta$-Rx $(P<0.001)$ (Table I). While the content of most individual ceramide fractions is increased, the change in ceramide 4 is most impressive (Table I). Ceramide 4, a relatively minor component of SC sphingolipids from control animals, increases greater than sixfold in $\beta-R x$ pups to become the most prevalent ceramide fraction. In contrast, the nonpolar ceramide fractions (ceramides 1 and 2) are only modestly increased (less than twofold). Finally, the content of SC cholesterol increases threefold in response to $\beta$ - Rx $\left(6.09 \pm 0.66\right.$ vs. $18.96 \pm 3.68 \mu \mathrm{g}$ cholesterol $/ \mathrm{cm}^{2}$, control vs. $\beta$ $\mathrm{Rx} ; P<0.02)$. These data demonstrate that glucocorticoid treatment increases the overall lipid content of SC in the fetal rat, including its cholesterol and ceramide content.

\section{Discussion}

In the fetal rat the cutaneous permeability barrier first appears during the 20th d of fetal life (6). Hence, pups of $19 \mathrm{~d} \mathrm{GA}$ have no measurable barrier to water loss, while by $21 \mathrm{~d} \mathrm{GA}$ all pups exhibit competent barriers, with further modest increments in barrier competence developing over the next few days, before and following birth (6). In these studies we have demonstrated that maternal glucocorticoid treatment accelerates maturation of the permeability barrier in the fetal rat, with a competent barrier present in most treated pups at $19 \mathrm{~d}$ GA (c.f., Fig. 1).

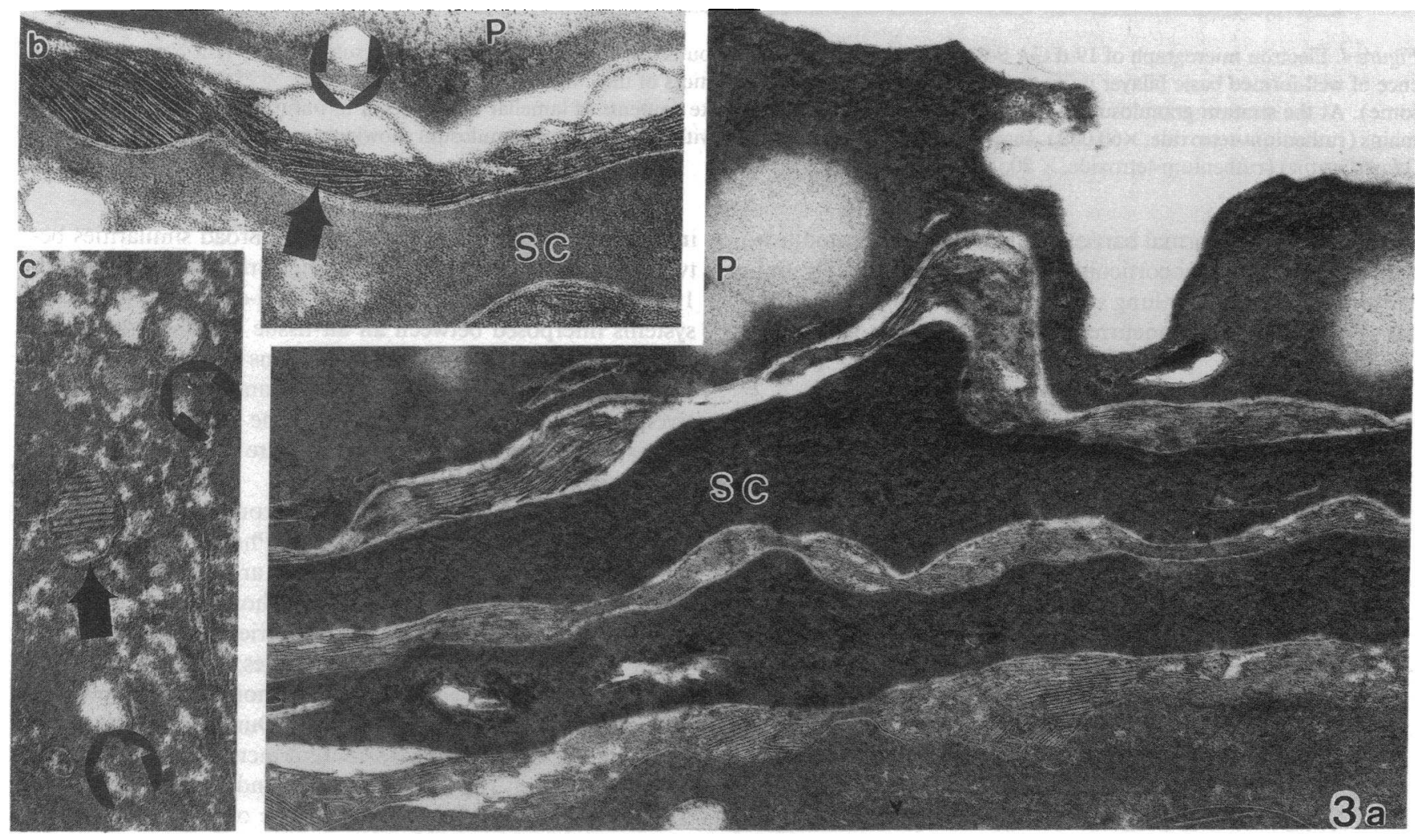

Figure 3. Representative electron micrograph of 19-d GA control epidermis illustrating the outermost peridermal layer $(P)$ and subjacent SC $(a)$. Note the persistence of unprocessed, disclike membrane structures throughout the SC interstices. Empty-appearing foci within the intercellular domains are also present throughout the SC (ruthenium-tetroxide, $\times 7200)$. (b) Inset demonstrates a higher magnification of SC interstices. Regions with lamellar structures (closed arrows) alternate with empty-appearing spaces (open arrows). Membranes are not organized into lamellar unit structures (ruthenium-tetroxide, $\times 15,000$ ). Within the stratum granulosum $(c)$ (inset), most lamellar bodies lack lamellar contents, thus appearing empty (open arrows). Occasionally lamellar bodies exhibit a complete lamellar substructure (closed arrow) (ruthenium-tetroxide, $\times 80,000)$ 


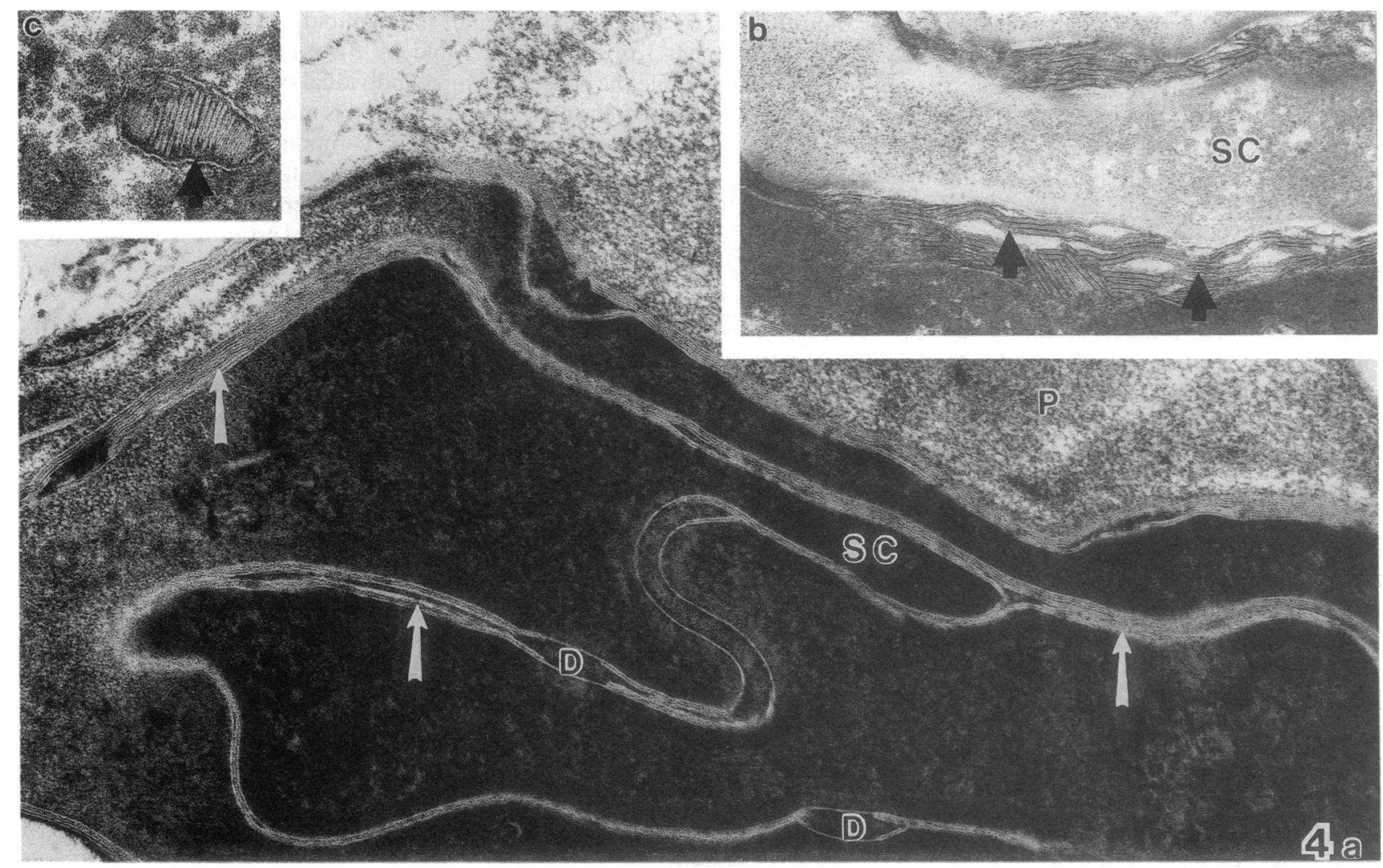

Figure 4. Electron micrograph of 19-d GA $\beta$-Rx epidermis illustrating the outermost peridermal layer $(P)$ and subjacent SC $(a)$. Note the presence of well-formed basic bilayer unit structures (arrows) filling the interstices of the entire SC (ruthenium-tetroxide, $\times 75,000)(D$, desmosome). At the stratum granulosum/SC interface $(b)$ inset, secreted disclike contents of lamellar bodies begin to unfurl in the intercellular domains ( ruthenium-tetroxide, $\times 60,000$ ). Inset $c$ illustrates a lamellar body within the stratum granulosum showing a mature lamellar substructure (closed arrow) (ruthenium-tetroxide, $\times 80,000$ ).

The timetable for normal barrier ontogenesis and its modification by maternal glucocorticoid treatment is remarkably similar to that observed for lung surfactant maturation in the fetal rat $(17,18,28)$. This concurrence becomes even more intrigu-

Table I. 19-Day Fetal Rat SC Sphingolipid Content and Composition: Betamethasone-treated vs. Control

\begin{tabular}{lccc}
\hline & \multicolumn{2}{c}{$\begin{array}{c}\text { Lipid content } \\
\left(\mu \mathrm{g} \text { lipid/cm } \mathrm{cm}^{2} \text { mean } \pm \mathrm{SE}\right)\end{array}$} & \\
\cline { 2 - 3 } Ceramide fraction & Betamethasone & Control & Fold increase \\
\hline Cer 1 & $3.50 \pm 0.28^{*}$ & $2.16 \pm 0.41$ & 1.6 \\
Cer 2 & $3.52 \pm 0.28^{\S}$ & $2.27 \pm 0.24$ & 1.6 \\
Cer 3 & $4.58 \pm 0.48^{\S}$ & $1.51 \pm 0.23$ & 3.0 \\
Cer 4 & $5.26 \pm 0.45^{\S}$ & $0.81 \pm 0.25$ & 6.5 \\
Cer 5 & $1.96 \pm 0.26$ & $0.86 \pm 0.11$ & 2.3 \\
Cer 6 & $1.29 \pm 0.27^{\ddagger}$ & $0.19 \pm 0.08$ & 6.8 \\
Cer 7 & $4.16 \pm 0.63^{\S}$ & $1.21 \pm 0.20$ & 3.5 \\
Total SPL & $27.51 \pm 2.72^{\S}$ & $10.87 \pm 1.48$ & 2.5 \\
& & & \\
\hline
\end{tabular}

Maternal rats were injected with betamethasone or saline (control) ( 2 maternal rats each group) on day 16,17 , and 18 of gestation. On day 19, 3-7 pups from each litter were killed and their SC lipids extracted and sphingolipid (SPL) content quantified by scanning densitometry. Ceramide fractions are designated 1 to 7 in order of decreasing Rf.

${ }^{*} P<0.02$. ${ }^{\ddagger} P<0.01$. ${ }^{\circledR} P<0.001$. ing when considered in light of certain broad similarities between the epidermal barrier and lung surfactant systems ( 10 , 19, 20, 29). Both are extracellular, lipid-enriched membrane systems interposed between an air-tissue interface. And both membrane systems derive from analogous lipid-enriched secretory organelles, the epidermal and lung lamellar bodies, respectively. These similarities suggest that the lung surfactant and epidermal barrier lipid systems may share common regulatory mechanisms.

Despite these broad similarities, the compositions of surfactant and barrier lipids are very different. Phospholipids, particularly dipalmitoylphosphatidylcholine, are the predominant lipid in surfactant (20). In contrast, phospholipids are strikingly absent in SC lipid bilayers, and barrier lipids are predominantly composed of a family of ceramides, free fatty acids, and cholesterol, thus providing a uniquely nonpolar milieu highly suited to retardation of water loss (11). During normal development in the fetal rat, SC lipid content increases approximately twofold between gestational days 19 and 21 as a competent barrier is established (6). Similarly, we observed an approximate twofold increase in SC lipid content of 19-d GA rat pups treated with glucocorticoids. These data are consistent with prior observations that SC lipid content is positively correlated with barrier competence in mature mammalian skin $(23,27$, 30 ) and suggest that increasing lipid content in fetal SC may be an essential factor in the functional maturation of the permeability barrier. In mature skin, barrier lipids derive in part, if 
not predominantly, from epidermal de novo synthesis, and epidermal lipid synthesis is regulated by barrier requirements (31). In fetal lung, glucocorticoids regulate phosphatidylcholine synthesis (19). It will be important, therefore, in future studies to determine whether glucocorticoids regulate fetal epidermal lipid synthesis.

The effects of glucocorticoids on the SC content of specific lipid fractions differed somewhat from those observed during normal ontogenesis, particularly in the relative proportion of nonpolar vs. polar ceramide fractions. During normal development the SC content of the most nonpolar ceramide fractions increases approximately fivefold between gestational days 19 and 21 (6). These fractions would include the acylceramide, a unique epidermal species in which linoleic acid ( $\mathrm{C18:2})$ is esterified to the $\omega$ terminus of a very long chain (C30-C34), $n$-acyl $\alpha$-hydroxy fatty acid $(32,33)$. This species is postulated to be of particular importance for barrier function (34). In contrast, during glucocorticoid-induced barrier ontogenesis, the SC content of the most nonpolar ceramide fractions is only modestly increased ( $\sim 1.5$-fold ) by $\beta$-Rx, while the content of a more polar fraction, ceramide 4 , increases $\sim 6$-fold (c.f., Table I). It will be important in future studies to determine the structure of ceramide 4 in order to pinpoint which step(s) in the sphingolipid metabolic pathway may be regulated by glucocorticoids.

In mature SC, lipids are arranged into multiple, broad lamellar bilayers, forming characteristic unit structures $(15,16$, 35 ). During normal fetal rat development, secreted lamellar body contents are evident within the intercellular domains of day $19 \mathrm{SC}$, but they are not transformed into basic lamellar unit structures (6). Subsequently, the presence of a competent barrier on gestational day 21 correlates with a mature membrane pattern of SC lipids that show characteristic fluorescence by nile red histochemistry, and the extension of basic lamellar unit structures throughout the layers of the SC (6). In this study we have shown that $19-\mathrm{d} \beta$-Rx rat epidermis also exhibits a mature pattern of nile red fluorescence and well-formed lamellar unit structures throughout the SC (c.f., Figs. 2, 4). Taken together these data suggest that the formation of lamellar unit structures throughout the SC interstices may be a critical requirement for barrier competence. This hypothesis is further supported by observations of structural abnormalities of SC lamellae in mature rodent skin in which the barrier has been abrogated either by solvent extraction of SC lipids (14), by essential fatty acid deficiency (16), or by inhibition of epidermal cholesterol synthesis (36). Furthermore, in certain inherited scaling diseases, abnormalities in SC lamellar unit substructure (37) may underlie impaired barrier function (38). Both barrier lipid $(10,14)$ and lung surfactant $(20)$ membranes undergo a series of transformations following lamellar body secretion. In lung, surfactant apoproteins facilitate these transformations (39-41), and the expression of two surfactant apoproteins is regulated by glucocorticoids (19). Whether comparable extracellular proteins facilitate barrier lipid membrane transformations is unknown, but these data suggest that the factors that underlie the transformation of stratum corneum lipid bilayers into lamellar unit structures are hormonally regulated.

Maternal treatment with glucocorticoids in the face of impending premature delivery is frequently employed to promote fetal lung maturation (reviewed in 42). However, in view of the recent success of surfactant replacement therapies $(43,44)$, pulmonary indications for this treatment may decrease. If so, other benefits of maternal glucocorticoid treatment will have to be weighed against known and potential adverse effects $(42,45$, 46). While clinically, skin maturation of the premature infant appears to be accelerated by maternal glucocorticoid treatment (42), glucocorticoids did not accelerate skin maturation in the fetal rabbit (47). However, these authors employed a global scale weighted toward hair follicle maturation; neither functional maturation of the barrier nor maturation of the lamellar body secretory system was assessed (47). The demonstration herein that glucocorticoids accelerate barrier maturation in the fetal rat indicates that follow-up clinical studies are urgently needed to determine whether glucocorticoid treatment reduces the morbidity and mortality attributable to barrier immaturity in the premature infant.

\section{Acknowledgments}

The authors thank Joanne Buehler and Robin Stierwalt for technical assistance, Bil Chapman for manuscript preparation, and Dr. Peter M. Elias for review of the manuscript.

The work was supported in part by grants from the National Institutes of Health (AR 29908, AR 39639), the Medical Research Service of the Department of Veterans Affairs Medical Center and the Society for Pediatric Research (student research award).

\section{References}

1. Nachman, R. L., and N. B. Esterly. 1971. Increased skin permeability in preterm infants. J. Pediatr. 79:628-632.

2. Hammarlund, K., and G. Sedin. 1979. Transepidermal water loss in newborn infants. III. Relation to gestational age. Acta Paediatr. Scand. 68:795-801.

3. Wilson, D. R., and H. I. Maibach. 1980. Transepidermal water loss in vivo. Preterm and term infants. Biol. Neonate. 37:180-185.

4. Rutter, N., and D. Hull. 1979. Water loss from the skin of term and preterm babies. Arch. Dis. Child. 54:858-868.

5. Kurihara-Bergstrom, T., W. R. Good, C. Signor, and M. Woodwroth. 1990. Epidermal differentiation and permeability in fetal pig skin. Pharmacol. Res 7:1,201-1,204.

6. Aszterbaum, M., G. K. Menon, K. R. Feingold, and M. L. Williams. 1991. Ontogeny of the epidermal barrier to water loss in the rat: Correlation of function with stratum corneum structure and lipid content. Pediatr. Res. 31:308-317.

7. Hammarlund, K., B. Stromberg, and G. Sedin. 1986. Heat loss from the skin of preterm and full term newborn infants during the first weeks after birth. Biol. Neonate. 50:1-10.

8. Maurer, A., J. L. Micheli, Y. Schuetz, D. Freymound, and E. Jequier. 1984 Transepidermal water loss and resting energy expenditure in preterm infants. Helv. Paediatr. Acta. 39:405-418.

9. Vernon, H. J., A. T. Lane, L. J., Wischerath, J. M. Davis, and M. A. Menegus. 1990. Semipermeable dressing and transepidermal water loss in premature infants. Pediatrics $86: 357-362$.

10. Elias, P. M., and G. K. Menon. 1991. Structural and lipid biochemical correlates of the epidermal permeability barrier. Adv. Lipid Res. 24:1-26.

11. Schurer, N. S., and P. M. Elias. 1991. The biochemistry and function of epidermal lipids. Adv. Lipid Res. 24:27-56.

12. Grayson, S., A. G. Johnson-Winegar, B. U. Wintroub, E. H. Epstein, Jr., and P. M. Elias. 1985. Lamellar body enriched fractions from neonatal mice. Preparative techniques and partial characterization. J. Invest. Dermatol. 85:289295.

13. Wertz, P. W., D. T. Downing, R. K. Freinkel, and T. N. Traczyk. 1984. Sphingolipids of the stratum corneum and lamellar granules of fetal rat epidermis. J. Invest. Dermatol. 83:193-195.

14. Menon, G. K., K. R. Feingold, and P. M. Elias. 1992. The lamellar body secretory response to barrier disruption. J. Invest. Dermatol. 98:279-289.

15. Schwartzendruber, D. C., P. W. Wertz, D. J. Kito, K. C. Madison, and D. T. Downing. 1989. Molecular models of the intercellular lipid lamellae in mammalian stratum corneum. J. Invest. Dermatol. 92:251-257.

16. Hou, S. Y. E., A. K. Mitra, S. H. White, G. K. Menon, R. Ghadially, and P. M. Elias. 1991. Membrane structures in normal and essential fatty acid deficient stratum corneum: characterization by ruthenium tetroxide staining and x-ray diffraction. J. Invest. Dermatol. 96:215-223. 
17. Bourbon, J. R., P. M. Farrell, E. Doncet, D. J. Brown, and C. Valenza. 1987. Biochemical maturation of fetal rat lung: A comprehensive study including surfactant determination. Biol. Neonate. 52:48-60.

18. Schellhase, D. E., P. A. Emrie, J. H. Fisher, and J. M. Shannon. 1989 Ontogeny of surfactant apoproteins in the rat. Pediatr. Res. 26:167-174.

19. Ballard, P. L. 1989. Hormonal regulation of pulmonary surfactant. Endocr. Rev. 10:165-178.

20. VanGolde, M. G., J. J. Batenburg, and B. Robertson. 1988. The pulmonary surfactant system: Biochemical aspects and functional significance. Physiol. Rev. 68:374-455.

21. Menon, G. K., K. R. Feingold, A. H. Moser, B. E. Brown, and P. M. Elias. 1985. De novo sterologenesis in the skin. II. Regulation by cutaneous barrier requirements. J. Lipid Res. 26:418-427.

22. Feingold, K. R., M. Mao-Qiang, E. Proksch, G. K. Menon, B. Brown, and P. M. Elias. 1991. The lovastatin-treated rodent: a new model of barrier disruption and epidermal hyperplasia. J. Invest. Dermatol. 96:201-209.

23. Lampe, M. A., A. L. Burlingame, J. Whitney, M. L. Williams, B. E. Brown, E. Roitman, and P. M. Elias. 1983. Human stratum corneum lipids: characterization and modulation during differentiation. J. Lipid Res. 24:120 130.

24. Ponec, M., A. Weerheim, J. Kempenaar, A. M. Mommas, and D. H. Nugteren. 1988. Lipid composition of cultured human keratinocytes in relation to their differentiation. J. Lipid Res. 29:945-961.

25. Fowler, S. D., and P. H. Greenspan. 1985. Application of nile red, fluorescent hydrophobic probe, for the detection of neutral lipid deposits in tissue sections. J. Histochem. Cytochem. 33:833-836.

26. Sicard, R. E., and J. C. Werner. 1992. Dexamethasone induces a transient relative cardiomegaly in neonatal rats. Pediatr. Res. 31:359-363.

27. Grubauer, G., K. R. Feingold, and P. M. Elias. 1989. Lipid content and lipid types as determinants of the epidermal permeability barrier. J. Lipid Res. 30:89-96.

28. Shimizu, H., K. Migamura, and Y. Kuroki. 1991. Appearance of surfactant proteins, SP-A and SP-B, in developing rat lung and the effects of in vivo dexamethasone treatment. Biochim. Biophys. Acta. 1081:53-60.

29. Williams, M. L. 1991. Composition of skin lipids. In Fetal and Neonatal Physiology. R. A. Polin and W. W. Fox, editors. W. B. Saunders, Co., Philadelphia. 552-554.

30. Elias, P. M., E. R. Cooper, A. Korc, and B. E. Brown. 1981. Percutaneous transport in relation to stratum corneum structure and lipid composition. $J$ Invest. Dermatol. 76:297-301.

31. Feingold, K. R. 1991. The regulation and role of epidermal lipid synthesis. Adv. Lipid Res. 24:57-82.

32. Bowser, P. A., D. H. Nugteren, R. J. White, U. M. T. Houtsmiller, and C Prottey. 1985. Identification, isolation and characterization of epidermal lipids containing linoleic acid. Biochem. Biophys. Acta. 834:419-420.

33. Wertz, P. W., and D. T. Downing. 1983. Ceramides of pig epidermis: structure determination. J. Lipid Res. 24:759-765.
34. Wertz, P. W., and D. T. Downing. 1982. Glycolipids in mammalian epidermal structure and function in the water barrier. Science (Wash. DC). 217:1,261-1,262.

35. Madison, K. C., D. C. Swartzendruber, P. W. Wertz, and D. T. Downing. 1987. Presence of intact intercellular lamellae in the upper layers of the stratum corneum. J. Invest. Dermatol. 88:714-718.

36. Menon, G. K., K. R. Feingold, M.-Q. Man, M. Schaude, and P. M. Elias. 1992. Structural basis for the barrier abnormality following inhibition of HMG CoA reductase in murine epidermis. J. Invest. Dermatol. 98:209-219.

37. Ghadially, R., M. L. Williams, S. Y. E. Hou, and P. M. Elias. 1992. Membrane structural abnormalities in the stratum corneum of the autosomal recessive ichthyoses. J. Invest. Dermatol. 99:755-763.

38. Frost, P., G. D. Weinstein, J. W. Bothwell, and R. Wildnauer. 1968. Ichthyosiform dermatoses. III. Studies of transepidermal water losses. Arch. Dermatol. 98:230-233.

39. Takahashi, A., and T. Fujiwara. 1986. Proteolipid in bovine lung surfactant: its role in surfactant function. Biochem. Biophys. Res. Commun. 136:527532.

40. Hawgood, S., B. J. Benson, D. Schilling, D. Damon, J. A. Clements, and R. T. White. 1987. Nucleotide and amino acid sequences of pulmonary surfactant protein SP18 and evidence for cooperation between SP18 and SP28-36 in surfactant lipid absorption. Proc. Natl. Acad. Sci. USA. 84:66-70.

41. Susuki, Y., Y. Fujita, and K. Kogishi. 1989. Reconstitution of tubular myelin from synthetic lipids and proteins associated with pig pulmonary surfactant. Am. Rev. Respir. Dis. 140:75-81.

42. Ballard R. A. 1986. Antenatal glucocorticoid therapy: clinical effects. In Hormones and Lung Maturation. P. L. Ballard, editor. Springer-Verlag, Berlin. 137-172.

43. Corbet, A., R. Bucciarelli, S. Goldman, M. Mammel, D. Wold, W. Long, and the American Exosorf Pediatric Study Group. 1991. Decreased mortality rate among small premature infants treated at birth with a single dose of synthetic surfactant: A multicentered controlled trial. J. Pediatr. 118:277-284.

44. Kendig, J. W., R. H. Notter, C. Cox, J. Reubens, J. M. Davis, W. M. Maniscalco, R. A. Sinkin, A. Bartoletti, H. S. Dweck, M. J. Horgan, H. Risenberg, D. L. Phelps, and D. L. Shapiro. 1991. A comparison of surfactant as immediate prophylaxis and as rescue therapy in newborns of less than 30 weeks' gestation. N. Engl. J. Med. 324:865-871.

45. Hou, Q.-C., and T. A. Slotkin. 1989. Effects of prenatal dexamethasone or terbutaline exposure on development of neural and intrinsic control of heart rate. Pediatr. Res. 26:554-557.

46. Navarro, H. A., J. Lachowicz, J. Bartolone, W. L. Whitmore, and T. A. Slotkin. 1988. Effects of prenatal dexamethasone on development of ornithine decarboxylase activity in brain and peripheral tissues of rats. Pediatr. Res. 24:465-469.

47. Taeusch, H. W., Jr., N. S. Wang, and M. A. Avery. 1972. Studies on organ maturation: "Skin age" as an indicator of "lung age" in fetal rabbits. Pediatrics. 49:400-405. 